\title{
Gastrointestinal Autonomic Nerve Tumor
}

National Cancer Institute

\section{Source}

National Cancer Institute. Gastrointestinal Autonomic Nerve Tumor. NCI Thesaurus.

Code C27940.

A variant of gastrointestinal stromal tumor with ultrastructural features of neural differentiation. It is composed of spindle or epithelioid neoplastic cells. 